\title{
Different effects of oxycodone and remifentanil in patients undergoing ultrasound-guided percutaneous radiofrequency ablation of hepatic cancer: a randomized trial
}

This article was published in the following Dove Medical Press journal:

Drug Design, Development and Therapy

Junbei $\mathrm{Wu}^{1, *}$

Yunhong $\mathrm{Lu}^{2, *}$

Xiaofei Cao'

'Department of Anesthesiology,

The First Affiliated Hospital of Nanjing Medical University, Nanjing, Jiangsu Province, China; ${ }^{2}$ Department of Anesthesiology, The Second Affiliated Hospital of Nanjing Medical University, Nanjing, Jiangsu Province, China

*These authors contributed equally to this work
Correspondence: Xiaofei Cao Department of Anesthesiology, The First Affiliated Hospital of Nanjing Medical University, 300 Guangzhou Road, Nanjing, Jiangsu Province 210029, China Tel +86 I358400 2389

Email xiaofei_cao@sina.com

\begin{abstract}
Background: Percutaneous radiofrequency ablation (RFA) is a recently introduced alternative technique for the treatment of hepatic cancer. Anesthesia is required for RFA of hepatic cancer to achieve patient comfort and immobilization during this painful procedure. The purpose of this study was to investigate the analgesic efficacy and evaluate the safety of a single intravenous injection of oxycodone hydrochloride for this procedure.

Patients and methods: A total of 120 American Society of Anesthesiologists class I-II grade patients for elective ultrasound-guided percutaneous RFA were enrolled in this randomized controlled trial. Patients were randomized (1:1) to receive either a single intravenous injection of oxycodone (group O) or continuous infusion of remifentanil (group R). Both groups received the continuous infusion of dexmedetomidine for sedation. Visual analog scale (VAS), rescue analgesic, and side effects were checked during the periprocedural period. In addition, patient and oncologist satisfaction on a scale of 1-5 were determined.

Results: VAS score in group $\mathrm{O}$ was significantly lower than in group $\mathrm{R}$ at 1, 2, and 3 hours after RFA, and patients in group $\mathrm{O}$ required analgesics significantly later and less doses in the first 24 hours after RFA. The occurrence of unwanted body movements was significantly lower in group $\mathrm{O}$. We found no complications including allergic reaction, excessive sedation, and chest wall rigidity in all patients. The patient satisfaction score was significantly higher in group $\mathrm{O}$ than that in group $\mathrm{R}$. Conclusion: Ultrasound-guided percutaneous RFA for hepatic cancer can be completed both with continuous infusion of remifentanil or a single intravenous injection of oxycodone. However, oxycodone hydrochloride provides better patient experience with higher satisfactory score and less unwanted body movements, relieves post-procedural pain better, and is not associated with an increase in adverse effects.
\end{abstract}

Keywords: analgesia, oxycodone, hepatic cancer, radiofrequency ablation

\section{Introduction}

Percutaneous radiofrequency ablation (RFA) is a recently introduced alternative technique for the treatment of hepatic cancer since 1990s. ${ }^{1}$ In RFA procedure, an electrode is inserted into the lesion under real-time ultrasound or computed tomography (CT) guidance. ${ }^{2,3}$ A high-frequency alternating current delivered through the electrode produces coagulative necrosis of the tumor. Temperatures often approach or exceed $100^{\circ} \mathrm{C}$, which results in tissue necrosis and cellular protein denaturation. ${ }^{4}$

Most of percutaneous RFA procedures are performed by oncologists or interventional radiologists outside operation rooms. However, many patients complain 
of obvious pain during RFA, and sometimes the treatment has to be terminated because of this insufferable pain. So, strategies of intraprocedural sedation or anesthesia should be considered. Several anesthesia methods, including local, epidural, 5,6 and general anesthesia (GA) $)^{5-7}$ and intravenous sedation (IV sedation) ${ }^{8}$ can be utilized in RFA. Since RFA is minimally invasive and the duration is relatively short, most of these procedures are performed by radiologists or oncologists outside the operating room in our center. Hence, sedation is increasingly demanded in RFA management. ${ }^{9}$ Goal of sedation is to reduce fear, anxiety, and pain, facilitate satisfaction, as well as ensure safety during the procedure.

Continuous infusion of remifentanil for pain control is often used in painful procedures, with a rapid onset and a short half-life. ${ }^{10,11}$ Though analgesic effect of remifentanil was strong during the procedure, discontinuation can induce sudden onset of pain. Oxycodone is a semisynthetic opioid agonist with longer duration of action. ${ }^{12}$ It is commonly given for post-procedural pain control in interventional radiology. ${ }^{13}$ Here, we conducted this study to investigate the analgesic efficacy of a single infusion of oxycodone in patients undergoing percutaneous RFA of hepatic cancer.

\section{Patients and methods}

\section{Patient enrollment}

The study was conducted in accordance with the Declaration of Helsinki. It was conducted at The First Affiliated Hospital of Nanjing Medical University after approval from the institute's ethics committee. Written informed consent was obtained from each patient. A total of 120 patients undergoing elective percutaneous RFA of hepatic cancer were enrolled in this study. The inclusion criteria were being 1) aged 30-65 years old, 2) American Society of Anesthesiologists (ASA) class I-II, 3) Child-Pugh score as class A, 4) single tumor lesion to be treated, and 5) liver and renal function tests in normal range. The exclusion criteria were 1) use of sedatives and analgesics previously, and 2) history of acute upper respiratory tract infections recently.

\section{Sedation and analgesia}

Anesthetic monitoring included electrocardiogram, heart rate $(\mathrm{HR})$, blood oxygen saturation $\left(\mathrm{SpO}_{2}\right)$, respiration rate (RR), and non-invasive blood pressure (BP). These indexes were measured using a Mindray T6 monitor (Mindray Inc., Shenzhen, China). All patients received $5 \mathrm{~L} / \mathrm{min}$ oxygen using a simple facemask. Patients were randomized to receive either a single intravenous injection of oxycodone (group O) or continuous infusion of remifentanil (group R). Both groups received dexmedetomidine (Jiangsu Hengrui Medicine Co., Ltd., Lianyungang, China) for sedation with the loading dose of $1 \mu \mathrm{g} / \mathrm{kg}$ over 15 minutes and the maintenance dose of $0.4 \mu \mathrm{g} / \mathrm{kg} / \mathrm{h}$. Group $\mathrm{O}$ received a single intravenous injection of oxycodone $0.1 \mathrm{mg} / \mathrm{kg}$ (normal saline dilution of $1 \mathrm{mg} / \mathrm{mL}$; Mundipharma, Vantaa, Finland) 15 minutes before the procedure. Group R received remifentanil infusion (1 mg remifentanil mixed with $50 \mathrm{~mL}$ normal saline solution; Yichang Renfu Inc., Yichang, China) at the initial dose of $0.1 \mu \mathrm{g} / \mathrm{kg} / \mathrm{min}$ simultaneously with dexmedetomidine. The dose of remifentanil was adjusted up or down $0.01 \mu \mathrm{g} / \mathrm{kg} / \mathrm{min}$ according to patient's reaction and $0.15 \mu \mathrm{g} / \mathrm{kg} / \mathrm{min}$ as the maximal dose. When the patient had obvious unwanted involuntary movements or complained of pain, bolus injection of remifentanil $25 \mu \mathrm{g}$ was administered. Standard anesthesia also consisted of $5 \mathrm{~mL}$ of $2 \%$ lidocaine injected locally. The patients were monitored for about 0.5 hours in recovery room after the RFA procedure and must score 9 out of a 10 modified Aldrete Scoring when shifted to their wards. Tramadol (Grunenthal Co Ltd, Stolberg, Germany) was administered and recorded as a rescue analgesic when requested by patients.

\section{Procedure}

Ultrasound-guided RFA procedures were performed by an oncologist who had $>5$ years of RFA experience. Patients were treated using a cool-tip radiofrequency generator system (Radio Frequency Generator S-1500; MedSphere International, Inc., Shanghai, China). Umbrella electrode (21-863451; MedSphere International, Inc.) was inserted into the lesion under real-time ultrasound guidance. After successful needle insertion into the lesion, the treatment was initiated.

\section{Monitoring index}

Vital signs including HR, mean arterial pressure, RR, and sedation levels assessed by the Ramsay sedation were recorded before anesthesia $\left(\mathrm{T}_{0}\right)$, at the beginning of the procedure $\left(\mathrm{T}_{1}\right)$, during the placement of the electrode $\left(\mathrm{T}_{2}\right)$, at the start of RFA $\left(\mathrm{T}_{3}\right), 5$ minutes after the start of RFA $\left(\mathrm{T}_{4}\right)$, at the end of RFA $\left(\mathrm{T}_{5}\right)$, time of wake up $\left(\mathrm{T}_{6}\right)$, time of entering post-anesthesia care unit (PACU) $\left(\mathrm{T}_{7}\right)$, and time of leaving PACU $\left(\mathrm{T}_{8}\right)$.

Pain was assessed using visual analog scale (VAS) of 0-10, where 0 indicates no pain and 10 indicates the worst pain imaginable. VAS pain scores were recorded at the time of wake up, and at 30 minutes, 1 hour, 2 hours, 3 hours, and 6 hours after the end of RFA. Time to first rescue analgesic 
and total dose within 24 hours were recorded. In addition, patient and oncologist satisfaction surveys on a scale of $1-5$ were conducted $(1=$ not at all satisfied, $2=$ dissatisfied, $3=$ okay, $4=$ satisfied, $5=$ very satisfied). Incidences of adverse events (AEs) (allergic reaction, excessive sedation, respiratory depression, chest wall rigidity, unwanted body movements, drowsiness, postoperative nausea, and vomiting) were recorded. We defined respiratory depression as experiencing one of the following conditions: 1) spontaneous respiratory rate $<8$ breaths/min, 2) $\mathrm{SpO}_{2}<90 \%$, or 3 ) respiratory arrest $>15$ seconds. In such cases, patients were aroused and instructed to take deep breaths.

\section{Statistical analyses}

Statistical software SPSS version 19 (SPSS Inc., IBM Corporation, Armonk, NY, USA) and GraphPad Prism version 7 (GraphPad Software, Inc., San Diego, CA, USA) were used for data processing. Data were expressed as mean \pm standard deviations for continuous variables or $n$ of patients (\%) for categorical data. Variance analysis between groups was compared using the two-sample Student's $t$-test for continuous variables. The Pearson's chi-squared or Fisher's exact test was used to analyze categorical data. Non-parametric data were analyzed using the two-sample Mann-Whitney U rank-sum test. Repeated measures data were compared using repeated measures ANOVA. $P<0.05$ for the difference was statistically significant.

\section{Result}

\section{Baseline characteristics and periprocedural data}

The study included a total of 120 patients ( 70 male $/ 50$ female; mean age $52.6 \pm 8.4$ years; age range $36-65$ years). All patients followed the standard protocol for anesthesia, analgesia, and procedure. The demographic data (Table 1) show that there were no significant differences between the two groups. The total ablation time was significantly shorter in group $\mathrm{O}$ than group $\mathrm{R}(P=0.025)$.

Table I Baseline characteristics and periprocedural data

\begin{tabular}{|c|c|c|c|}
\hline Characteristics & Oxycodone group & Remifentanil group & Statistical significance \\
\hline Age (years) & $53.68 \pm 7.96$ & $51.43 \pm 8.83$ & 0.145 \\
\hline Gender (male/female) & 37 (61.67\%)/23 (38.33\%) & $33(55.00 \%) / 27(45.00 \%)$ & 0.459 \\
\hline Weight (kg) & $65.06 \pm 8.48$ & $67.25 \pm 9.13$ & 0.716 \\
\hline Height $(\mathrm{cm})$ & $|67.52 \pm 7.7|$ & $166.13 \pm 7.64$ & 0.326 \\
\hline Body mass index $\left(\mathrm{kg} / \mathrm{m}^{2}\right)$ & $23.4 I \pm 3.18$ & $24.43 \pm 3.50$ & 0.100 \\
\hline Smoking & 29 (48.33\%) & $31(51.67 \%)$ & 0.715 \\
\hline Alcohol & $27(45.00 \%)$ & $20(33.33 \%)$ & 0.190 \\
\hline Hypertension & $25(4 I .67 \%)$ & $22(36.67 \%)$ & 0.575 \\
\hline Diabete mellitus & $12(20.00 \%)$ & $17(28.33 \%)$ & 0.286 \\
\hline ASA PSI/II & $26(43.33 \%) / 34(56.67 \%)$ & $28(46.67 \%) / 32(53.33 \%)$ & 0.714 \\
\hline Cause of tumor & & & 0.869 \\
\hline HBV & $34(56.67 \%)$ & $31(51.67 \%)$ & \\
\hline $\mathrm{HCV}$ & $5(8.33 \%)$ & $4(6.67 \%)$ & \\
\hline Metastatic & $12(20.00 \%)$ & $13(21.67 \%)$ & \\
\hline Others & $9(15.00 \%)$ & $12(20.00 \%)$ & \\
\hline Tumor size $(\mathrm{cm})$ & $2.77 \pm 1.25$ & $2.98 \pm I .4 \mid$ & 0.389 \\
\hline$\leq 3 \mathrm{~cm}$ & $39(65.00 \%)$ & $36(60.00 \%)$ & 0.572 \\
\hline$>3 \mathrm{~cm}$ & $21(35.00 \%)$ & $24(40.00 \%)$ & \\
\hline Tumor location & & & 0.695 \\
\hline The central part of the liver & 35 (58.33\%) & $37(61.67 \%)$ & \\
\hline Subcapsular & $6(10.00 \%)$ & $9(15.00 \%)$ & \\
\hline Subphrenic & $6(10.00 \%)$ & $4(6.67 \%)$ & \\
\hline Perivascular or perivisceral & $13(21.67 \%)$ & $10(16.67 \%)$ & \\
\hline \multicolumn{4}{|l|}{ Time (minutes) } \\
\hline Total ablation time & $13.8 \pm 2.5$ & $14.9 \pm 2.8$ & $0.025^{\mathrm{a}}$ \\
\hline Sedation time & $33.6 \pm 5.7$ & $34.8 \pm 4.9$ & 0.206 \\
\hline Recovery time & $8.2 \pm 2.2$ & $8.6 \pm 2.3$ & 0.276 \\
\hline Time in PACU & $24.5 \pm 5.3$ & $24.0 \pm 5.0$ & 0.633 \\
\hline
\end{tabular}

Notes: Data presented as mean \pm SD or $\mathrm{n}(\%)$ of patients. Continuous data were compared using the two-sample Student's $t$-test. Categorical data were compared using the Pearson's chi-squared or Fisher's exact test. ${ }^{a} P<0.05$ between the two groups.

Abbreviations: ASA PS, American Society of Anesthesiologists physical status; HBV, hepatitis B virus; HCV, hepatitis C virus; PACU, post-anesthesia care unit. 


\section{Level of sedation and vital signs}

Repeated measures ANOVA indicated significant differences between groups in terms of Ramsay sedation scale ( $P=0.000$; Figure 1A). Significant differences in $\mathrm{T}_{2}$ and $\mathrm{T}_{4}$ values between both groups were noted $(P=0.043,0.000)$.

As shown in Figure 1B, there was no significant difference between groups at each time in terms of HR. However, repeated measures ANOVA indicated a significant difference between groups in terms of mean blood pressure (MBP) $(P=0.018$; Figure 1C). There was a significant difference in $\mathrm{T}_{3}$ score between the groups $(P=0.047)$, but not in $\mathrm{T}_{0}, \mathrm{~T}_{1-2}$, and $\mathrm{T}_{4-8}$ scores.
Repeated measures ANOVA indicated a significant difference between groups in terms of RR ( $P=0.000$; Figure 1D). There was a significant difference between groups in $\mathrm{T}_{3}$ and $\mathrm{T}_{4}$ scores $(P=0.017,0.011)$, but not in $\mathrm{T}_{0-2}, \mathrm{~T}_{5-8}$ scores.

\section{Visual analog scale}

VAS was used to evaluate the severity of post-RFA pain. The number of data points used at each time is shown in the raw data (Table 2), and the trend is presented in Figure 2. Oxycodone hydrochloride was found to be superior to remifentanil with respect to the VAS scores at 1, 2, and 3 hours after RFA $(P=0.040,0.003,0.000)$, though there was no significant
A

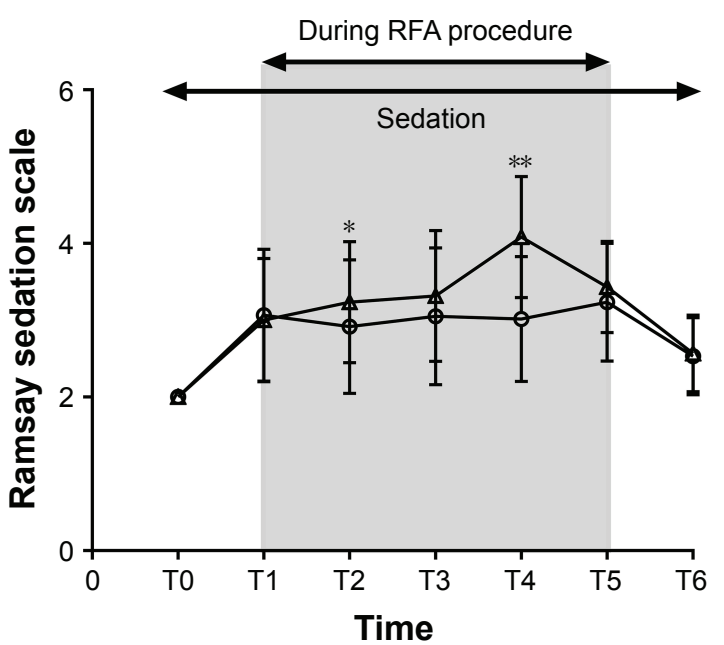

C

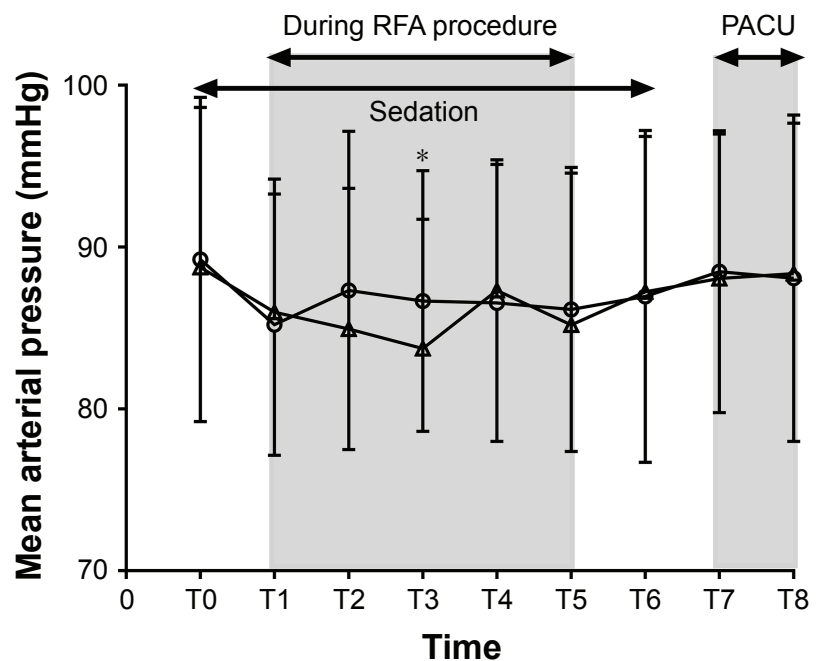

B

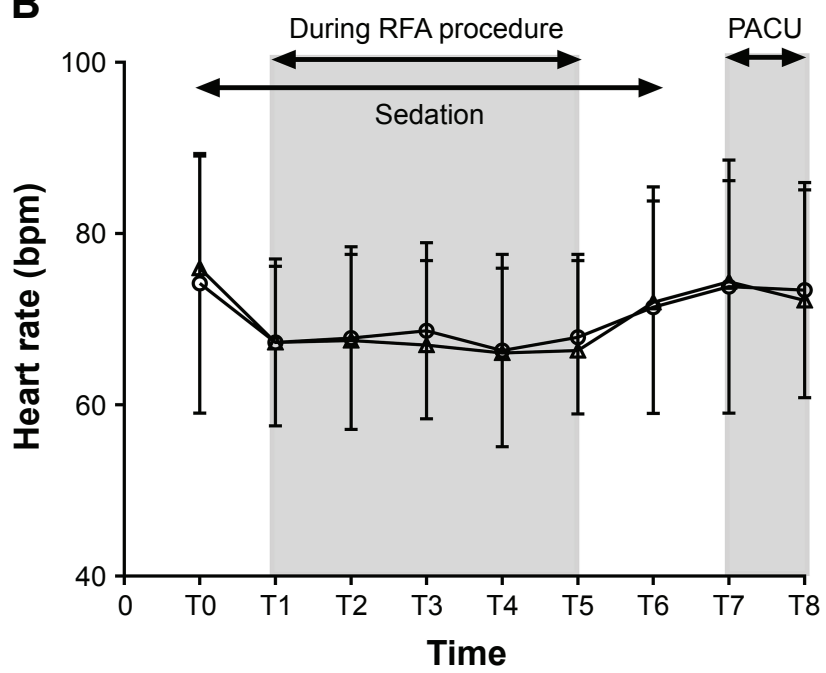

D

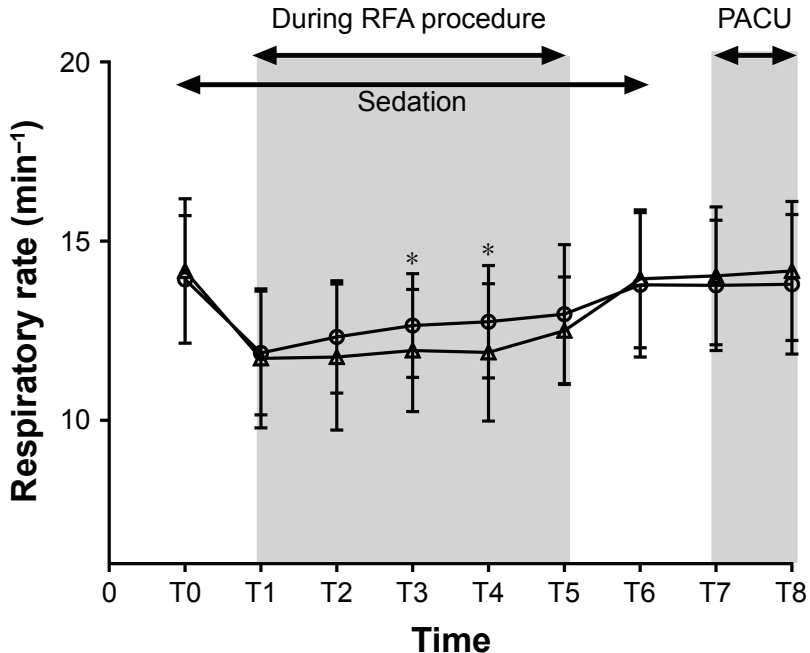

๑ Group O $\quad$ - Group R

Figure I Changes in Ramsay sedation scale and vital signs during periprocedural period.

Notes: Data are expressed as the mean $\pm S D$. $* P<0.05$ and $* * P<0.01$ when compared between groups, two-sample Student's $t$-test. Group $O=$ oxycodone group. Group $\mathrm{R}=$ remifentanil group.

Abbreviations: O, oxycodone; PACU, post-anesthesia care unit; R, remifentanil; RFA, radiofrequency ablation. 
Table 2 VAS at the indicated time points during the 6-hour period following RFA for both study groups

\begin{tabular}{l|l|l|l}
\hline VAS score & Oxycodone group & Remifentanil group & Statistical significance \\
\hline Time of wake up & $1.32 \pm 0.91$ & $1.44 \pm 1.01$ & 0.198 \\
30 minutes after RFA & $1.45 \pm 1.08$ & $1.70 \pm 1.38$ & 0.079 \\
\hline hour after RFA & $1.55 \pm 1.02$ & $1.82 \pm 1.50$ & $0.040^{*}$ \\
2 hours after RFA & $1.77 \pm 1.05$ & $2.11 \pm 1.32$ & $0.003^{*}$ \\
3 hours after RFA & $2.15 \pm 0.88$ & $2.73 \pm 1.26$ & $0.000^{*}$ \\
6 hours after RFA & $1.65 \pm 1.27$ & $1.79 \pm 1.32$ & 0.319 \\
\hline
\end{tabular}

Notes: Data are presented as mean $\pm S D$. $* P<0.05$, ${ }^{*} * P<0.0$ I, two-sample Mann-Whitney $U$ rank-sum test.

Abbreviations: RFA, radiofrequency ablation; VAS, Visual analog scale.

difference in VAS at the time of wake up, 30 minutes, and 6 hours after RFA.

Patients in group $\mathrm{R}$ required analgesics significantly earlier $(P=0.018$; Table 3$)$ and more $(P=0.014$; Table 3$)$ in the first 24 hours after RFA.

\section{Adverse events and satisfaction}

As shown in Table 4, no allergic reaction, excessive sedation, and chest wall rigidity occurred in either group. The incidence of unwanted body movements was significantly higher in group $\mathrm{R}(P=0.040)$. There were no differences in the incidence of respiratory depression, drowsiness, postoperative nausea, and vomiting.

The patient satisfactory score was significantly higher in the oxycodone group than that in the remifentanil group ( $P=0.045$; Figure 3$)$. Oncologist satisfaction was not significantly different between groups.

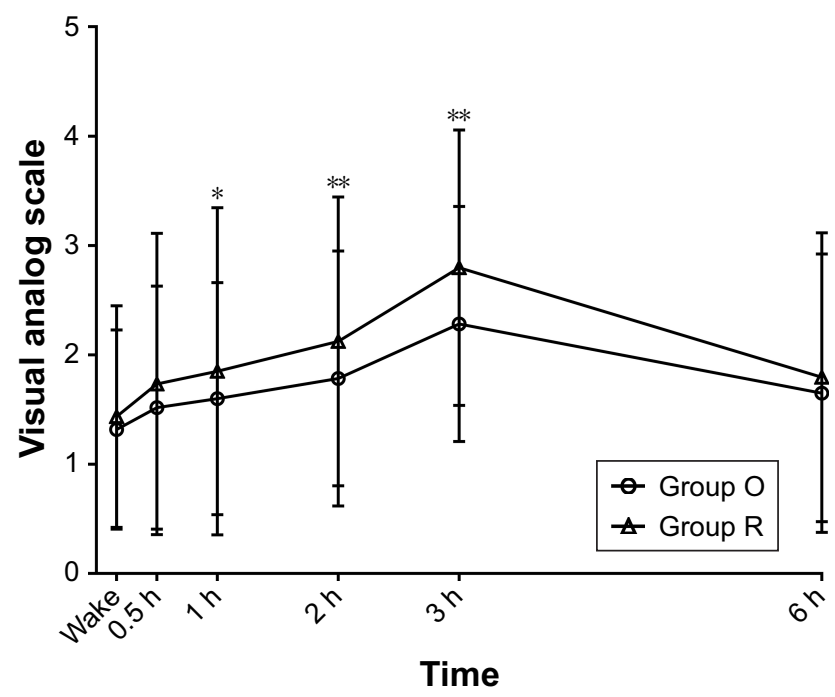

Figure 2 VAS at the indicated time points during the 6-hour period following RFA for both groups.

Notes: Data are expressed as the mean \pm SD. $* P<0.05$ and $* * P<0.01$ when compared between groups, two-sample Mann-Whitney $U$ rank-sum test. Group $\mathrm{O}=$ oxycodone group. Group R = remifentanil group.

Abbreviations: $\mathrm{O}$, oxycodone; $\mathrm{R}$, remifentanil; RFA, radiofrequency ablation; VAS, Visual analog scale.

\section{Discussion}

RFA is accepted as a safe and effective treatment for hepatic cancer, with minimal morbidity and mortality rates. Patients may feel anxiety and discomfort and suffer different degrees of pain during RFA. Patients with a larger lesion or multiple lesions and those with a longer procedure time reported more severe pain. ${ }^{14}$ It is more likely to cause severe pain when treating a tumor abutting the parietal peritoneum or a central tumor at close proximity to a large vessel. ${ }^{15}$ Some patients may even experience pain for several days or, occasionally, 1-2 weeks. ${ }^{16}$ Patients may refuse this procedure because of discomfort and anxiety.

There is evidence that percutaneous RFA procedure can be safely performed with proper administration of sedation and anesthesia. Choice of the anesthetic technique depends on the site, size, and number of lesions; ${ }^{17}$ patient condition and preference; clinician's recommendation; cultural differences; and cost effectiveness. Severe pain during the RFA procedure is often the main problem encountered under local anesthesia. Insufficient analgesia may lead to shortening of the ablation duration or terminating the procedure, which may result in an incomplete ablation and cancer recurrence. ${ }^{18}$ It seems that IV sedation and GA are superior to local anesthesia in sufficient ablation.

Both GA and IV sedation are used in this procedure. Using GA is particularly common in the developed countries. However, IV sedation technique with local anesthesia was also commonly used for the RFA procedure outside the operating room in China. Compared to GA, IV sedation also can provide ideal analgesia and excellent satisfaction, while patients generally have a shorter recovery time, reduced serious complications associated with GA, and pay less. The preferred type of IV sedation for RFA procedure is moderate sedation ("conscious sedation") for safe practice. ${ }^{19,20}$ If patients do not tolerate pain under IV sedation or the treatment is going to take longer time, GA is recommended. Chakravorty et al reported $66 \%$ of patients under sedation had to convert to GA, largely because of pain during passage of radiofrequency 
Table 3 Time to first rescue analgesic and the total number within 24 hours

\begin{tabular}{l|l|l|l}
\hline Parameters & Oxycodone group & Remifentanil group & Statistical significance \\
\hline Time of first analgesic (hours) & $6.84 \pm 3.80$ & $4.16 \pm 3.75$ & $0.018^{*}$ \\
\hline Within I hour & 0 & $10(16.7 \%)$ & $0.009 * *$ \\
Within 6 hours & $8(13.3 \%)$ & $13(21.7 \%)$ & \\
Within 24 hours & $11(18.3 \%)$ & $8(13.3 \%)$ & \\
Patients receiving analgesic & $13(21.7 \%)$ & $9(15.0 \%)$ & $0.014^{* *}$ \\
\hline Once & $6(10.0 \%)$ & $17(28.3 \%)$ & \\
Twice & 0 & $5(8.3 \%)$ & \\
\hline Thrice & & & \\
\hline
\end{tabular}

Notes: Data are presented as mean $\pm \mathrm{SD}$ or $\mathrm{n}$ of patients $(\%)$. $* \mathrm{P}<0.05$, two-sample Mann-Whitney $U$ rank-sum test. $* * P<0.05$, Pearson's chi-squared test.

current. ${ }^{17}$ However, whether GA is superior to sedation in terms of patient safety and complete tumor ablation rate during percutaneous RFA for hepatic cancer is uncertain. Lai et al demonstrated that treatment of small hepatocellular carcinoma by RFA under GA is associated with reduced risk of cancer recurrence, while no effect on overall survival was observed. ${ }^{5}$ Kuo et al showed that 2-year overall survival and recurrence-free survival rates were not significantly different in the GA group and in the non-GA (epidural and local anesthesia) group. ${ }^{6}$ Prospective randomized controlled clinical trials should be done to compare sedation and GA according to treatment outcomes. Many different medications are available ${ }^{21}$ for sedation, which vary depending on anesthesiologist preference and experience. In the past, we mostly used propofol alone for sedation in RFA, demonstrating better amnesia and comfort, but higher risk of respiratory depression or even apnea and hemodynamic depression. Also, there are more unwanted involuntary movements and poor compliance of breath holding during ultrasound location and puncturing in patients with sedatives alone, because of excessive sedation and not sufficient analgesic agent. Then opioids, either alone or combined with sedatives, were used in RFA, providing better comfort and tolerance. Intermittent midazolam and fentanyl were commonly used..$^{9,22,23}$ Remifentanil is also the preferred opioid in RFA procedure..$^{10,24-26}$ Remifentanil administered with continuous infusion is

Table 4 Adverse events

\begin{tabular}{l|l|l|l}
\hline Adverse events & Group O & Group R & P-value \\
\hline Allergic reaction & 0 & 0 & - \\
Excessive sedation & 0 & 0 & - \\
Chest wall rigidity & 0 & 0 & - \\
Unwanted body movements & $3(5.0 \%)$ & $10(16.7 \%)$ & $0.040 *$ \\
Respiratory inhibition & $2(3.3 \%)$ & $5(8.3 \%)$ & 0.436 \\
Drowsiness & $8(13.3 \%)$ & $5(8.3 \%)$ & 0.378 \\
Nausea & $7(11.7 \%)$ & $4(6.7 \%)$ & 0.343 \\
Vomiting & $4(6.7 \%)$ & $2(3.3 \%)$ & 0.675 \\
\hline
\end{tabular}

Notes: Data are presented as $n(\%)$ of patients. ${ }^{*} p<0.05$, Pearson's chi-squared or Fisher's exact test. Group $\mathrm{O}=$ oxycodone group. Group $\mathrm{R}=$ remifentanil group. Abbreviations: $O$, oxycodone; $R$, remifentanil. preferable as it provides good pain relief, with a rapid onset and a short duration of action, ${ }^{27}$ and there is little risk of delayed postoperative recovery. Oxycodone, as a type of double receptor agonist of opioid ( $\kappa$ receptor and weak affinity for $\mu$ receptor $),{ }^{28}$ has not been reported previously in RFA procedure. The purpose of this experiment was to investigate the efficacy of a single intravenous injection of oxycodone hydrochloride in patients undergoing ultrasound-guided percutaneous RFA and evaluate the safety during periprocedural period.

All patients in both groups completed the whole process. No RFA session was terminated in advance for the reason that patients could not tolerate pain. The duration of RFA procedure was a little longer in $\mathrm{R}$ group mainly due to pause and then modulating remifentanil infusion rate to obtain desired analgesic effect when patients reported obvious pain during puncturing and ablation. Furthermore, less unwanted body movements and better conscious state in group O may allow oncologists to complete the procedure in less time, due to good cooperation from the patients.

In the experiment, there was no significant difference at each time in terms of HR between the two groups. However, repeated measures ANOVA indicated a significant

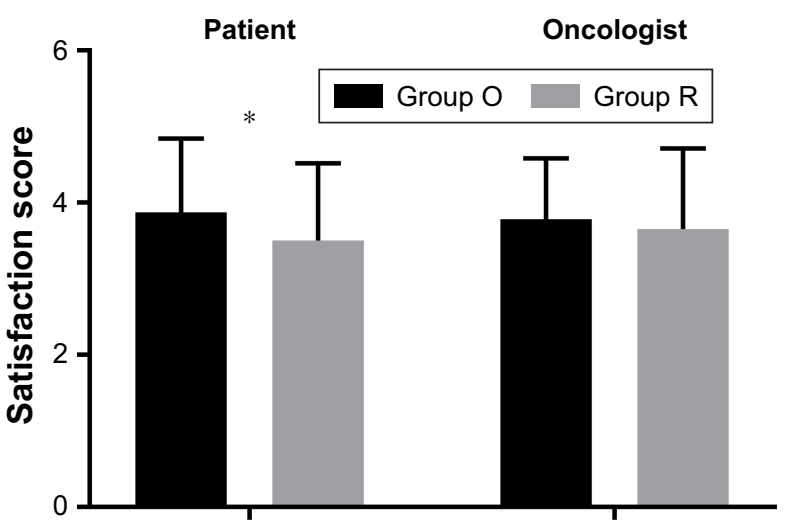

Figure 3 Differences in patient and oncologist satisfaction on a scale of $\mathrm{I}-5$ ( $\mathrm{I}=$ not at all satisfied, $2=$ dissatisfied, $3=$ okay, $4=$ satisfied, $5=$ very satisfied). Notes: Data are expressed as the mean $\pm S D$. $* P<0.05$, two-sample Mann-Whitney $\mathrm{U}$ rank-sum test. Group $\mathrm{O}=$ oxycodone group. Group $\mathrm{R}=$ remifentanil group. Abbreviations: $O$, oxycodone; $R$, remifentanil. 
difference between groups in terms of Ramsay sedation scale, MBP, and RR. Upregulation of infusion speed or bolus injection of remifentanil during RFA procedure may introduce cardiovascular and respiratory volatility and deepen sedation.

We found that oxycodone hydrochloride significantly reduced patient VAS score at 1, 2, and 3 hours after RFA, though there was no significant difference in VAS immediately at the time of wake up, 30 minutes, and 6 hours after RFA. Oxycodone exhibits a longer duration of action $\left(\mathrm{t}_{1 / 2}: 3.7-5.5\right.$ hours $)$. It has an antinociceptive action in the visceral pain system, ${ }^{29}$ which appears to be $\kappa$-opioid receptor mediated..$^{30}$ Therefore, oxycodone has better effect on relieving post-procedural pain of RFA. Furthermore, we found that patients in group $\mathrm{R}$ required analgesics significantly earlier and at greater doses in the first 24 hours after RFA. This is explained by extremely short elimination half-life of remifentanil. Furthermore, acute opioid tolerance and hyperalgesia during withdrawal may be other reasons. Even short-term infusion of remifentanil can cause hyperalgesia, ${ }^{31}$ and intra-operative remifentanil infusion rate threshold that induces hyperalgesia is still uncertain.

As an opioid analgesic, the side effects of oxycodone should still be considered, though at a lower rate in our study. Possible AEs are those common to opioids: mainly nausea, vomiting, constipation, drowsiness, dizziness, and pruritus. ${ }^{32}$ Serious AEs include respiratory depression or apnea, hypotension, cardiac arrest, and death. Hao et al reported no severe AEs with intravenous administration of oxycodone hydrochloride at a maximum dose of $10 \mathrm{mg}$ in Chinese patients. ${ }^{33}$ In our study, the most frequently occurring AEs were drowsiness $(13.3 \%)$ and nausea $(11.7 \%)$, for a single dose of $0.1 \mathrm{mg} / \mathrm{kg}$. Unwanted body movements that occurred during RFA were significantly less in group O. No chest wall rigidity occurred in either group. The incidence of respiratory depression was lower in group $\mathrm{O}$, though not significantly. Oxycodone and its active metabolite oxymorphone have $\mu$-opioid receptor agonist actions, which could be the reason for respiratory depression. ${ }^{34}$ In addition, oxycodone-induced respiratory depression was dose dependent. Although the incidence of respiratory depression was low, it should be paid special attention. The findings of the study suggested that oxycodone could be a safe analgesic drug in RFA.

There are some limitations in the study. First, the study was limited by a relatively small sample size, which limited the power of the statistical analysis. The number of patients with hepatic tumors who were in relatively good general health condition was relatively small. Patients with an ASA score of III-IV should be further assessed in our further research. Second, we did not use remifentanil with a targetcontrolled infusion modeling pump to adjust the rate of infusion to achieve a steady effect-site concentration in our study. Also, the question pertaining to the equivalent dose of the two drugs remains unsolved. We avoided increasing the dose of remifentanil to achieve the expected dose-related analgesic effect, which could also increase the incidence of side effects. Third, our study duration was short, spanning only 24 hours, which impaired the ability to assess rates of cancer recurrence.

\section{Conclusion}

In conclusion, ultrasound-guided percutaneous RFA for hepatic cancer can be completed both with continuous infusion of remifentanil or a single IV injection of oxycodone hydrochloride $(0.1 \mathrm{mg} / \mathrm{kg})$ combined with dexmedetomidine. However, oxycodone hydrochloride provides better experience for patients with higher satisfaction score and less unwanted body movements during this procedure. Also, oxycodone hydrochloride relieves post-procedural pain better, requires rescue analgesics later and less in the first 24 hours after RFA, and is not associated with an increase in adverse effects.

\section{Acknowledgment}

This research did not receive any specific grant from funding agencies in the public, commercial, or not-for-profit sectors.

\section{Disclosure}

The authors report no conflicts of interest in this work.

\section{References}

1. McGahan JP, Browning PD, Brock JM, Tesluk H. Hepatic ablation using radiofrequency electrocautery. Invest Radiol. 1990;25(3):267-270.

2. Curley SA, Izzo F. Radiofrequency ablation of primary and metastatic hepatic malignancies. Int J Clin Oncol. 2002;7(2):72-81.

3. Kim JW, Shin SS, Heo SH, et al. Ultrasound-Guided Percutaneous Radiofrequency Ablation of Liver Tumors: How We Do It Safely and Completely. Korean J Radiol. 2015;16(6):1226-1239.

4. Higgins H, Berger DL. RFA for liver tumors: does it really work? Oncologist. 2006;11(7):801-808.

5. Lai R, Peng Z, Chen D, et al. The effects of anesthetic technique on cancer recurrence in percutaneous radiofrequency ablation of small hepatocellular carcinoma. Anesth Analg. 2012;114(2):290-296.

6. Kuo YH, Chung KC, Hung CH, Lu SN, Wang JH. The impact of general anesthesia on radiofrequency ablation of hepatocellular carcinoma. Kaohsiung J Med Sci. 2014;30(11):559-565.

7. Bentley JN, Viswanathan A, Rosenberg WS, Patil PG. Treatment of medically refractory cancer pain with a combination of intrathecal neuromodulation and neurosurgical ablation: case series and literature review. Pain Med. 2014;15(9):1488-1495.

8. Amornyotin S, Jirachaipitak S, Wangnatip S. Anesthetic management for radiofrequency ablation in patients with hepatocellular carcinoma in a developing country. J Anesth Crit Care Open Access. 2015;3(1):00086. 
9. Sabo B, Dodd GD, Halff GA, Naples JJ, Jjjaj N. Anesthetic considerations in patients undergoing percutaneous radiofrequency interstitial tissue ablation. Aana J. 1999;67(5):467-468.

10. Joung KW, Choi SS, Jang DM, et al. Comparative effects of dexmedetomidine and propofol on US-guided radiofrequency ablation of hepatic neoplasm under monitored anesthesia care: a randomized controlled study. Medicine. 2015;94(32):e1349.

11. Park NS, Bae JI, Park AW, Won JH, Lee HS. Safety and effectiveness of analgesia with remifentanil for percutaneous transhepatic biliary drainage. AJR Am J Roentgenol. 2009;192(5):1430-1433.

12. Staahl C, Christrup LL, Andersen SD, Arendt-Nielsen L, Drewes AM. A comparative study of oxycodone and morphine in a multi-modal, tissue-differentiated experimental pain model. Pain. 2006;123(1-2): 28-36.

13. Ray CE Jr. Pain Management in Interventional Radiology; New York: Cambridge University Press; 2008.

14. Lee S, Rhim H, Kim YS, et al. Percutaneous radiofrequency ablation of hepatocellular carcinomas: factors related to intraprocedural and postprocedural pain. AJR Am J Roentgenol. 2009;192(4): 1064-1070.

15. Rhim H. Complications of radiofrequency ablation in hepatocellular carcinoma. Abdom Imaging. 2005;30(4):409-418.

16. Goldberg SN, Charboneau JW, Dodd GD, et al. Image-guided tumor ablation: proposal for standardization of terms and reporting criteria. Radiology. 2003;228(2):335-345.

17. Chakravorty N, Jaiswal S, Chakravarty D, Jain RK, Agarwal R. Anesthetic management of radiofrequency tumor ablation: our experience. 2006;50(2):123-127.

18. Kim HJ, Park BK, Chung IS. Comparison of general anesthesia and conscious sedation during computed tomography-guided radiofrequency ablation of T1a renal cell carcinoma. Can Assoc Radiol J. 2018; 69(1):24-29.

19. Practice guidelines for sedation and analgesia by non-anesthesiologists. Anesthesiology. 2002;96(4):1004-1017. Available from: http://anesthesiology. pubs.asahq.org/Article.aspx?articleid=1944958. Accessed January 3, 2019.

20. Martin ML, Lennox PH. Sedation and analgesia in the interventional radiology department. J Vasc Interv Radiol. 2003;14(9 Pt 1): 1119-1128.

21. Cashman JN, Ng L. The management of peri- and postprocedural pain in interventional radiology: a narrative review. Pain Manag. 2017;7(6): $523-535$.
22. Tobias JD, Leder M. Procedural sedation: A review of sedative agents, monitoring, and management of complications. Saudi J Anaesth. 2011; 5(4):395-410.

23. Maan M. Intravenous Administration of Fentanyl in Combination with Midazolam for Interventional Radiology Procedures in Adult Patients. 2013. Available from: https://posterng.netkey.at/esr/viewing/ index.php?module=viewing_poster \&task=\&pi=115162\&searchkey=3 8d9e2beb5f6dc5fb7079643f8e046fc. Accessed January 3, 2019.

24. Lencioni R, Della Pina C, Bartolozzi C, Cjai B. Percutaneous imageguided radiofrequency ablation in the therapeutic management of hepatocellular carcinoma. Abdom Imaging. 2005;30(4):401-408.

25. Ambrogi MC, Dini P, Melfi F, Mussi A, Ajjoto M. Radiofrequency ablation of inoperable non-small cell lung cancer. Journal of Thoracic Oncology. 2007;2(5):S2-S3.

26. Montgomery RS, Rahal A, Dodd GD, Leyendecker JR, Hubbard LG. Radiofrequency ablation of hepatic tumors: variability of lesion size using a single ablation device. American Journal of Roentgenology. 2004;182(3):657-661

27. Glass PSA, Gan TJ, Howell S. A review of the pharmacokinetics and pharmacodynamics of remifentanil. Anesthesia \& Analgesia. 1999; 89(Supplement):7-14.

28. Raffa RB, Pergolizzi JV, Segarnick DJ, Tallarida RJ. Oxycodone combinations for pain relief. Drugs Today. 2010;46(6):379-398.

29. De Schepper HU, Cremonini F, Park MI, Camilleri M. Opioids and the gut: pharmacology and current clinical experience. Neurogastroenterol Motil. 2004;16(4):383-394.

30. Ross FB, Smith MT. The intrinsic antinociceptive effects of oxycodone appear to be kappa-opioid receptor mediated. Pain. 1997;73(2):151-157.

31. Angst MS, Koppert W, Pahl I, Clark DJ, Schmelz M. Short-term infusion of the mu-opioid agonist remifentanil in humans causes hyperalgesia during withdrawal. Pain. 2003;106(1-2):49-57.

32. Ordóñez Gallego A, González Barón M, Espinosa Arranz E. Oxycodone: a pharmacological and clinical review. Clin Transl Oncol. 2007; 9(5):298-307.

33. Hao GT, Zhou HY, Gao HZ, et al. Pharmacokinetics of oxycodone hydrochloride and three of its metabolites after intravenous administration in Chinese patients with pain. Pharmacol Rep. 2014;66(1): 153-158.

34. Chang SH, Maney KM, Phillips JP, Langford RM, Mehta V. A comparison of the respiratory effects of oxycodone versus morphine: a randomised, double-blind, placebo-controlled investigation. Anaesthesia. 2010;65(10):1007-1012.
Drug Design, Development and Therapy

\section{Publish your work in this journal}

Drug Design, Development and Therapy is an international, peerreviewed open-access journal that spans the spectrum of drug design and development through to clinical applications. Clinical outcomes, patient safety, and programs for the development and effective, safe, and sustained use of medicines are the features of the journal, which
Dovepress

has also been accepted for indexing on PubMed Central. The manuscript management system is completely online and includes a very quick and fair peer-review system, which is all easy to use. Visit http://www.dovepress.com/testimonials.php to read real quotes from published authors. 